\title{
Determinants of Under-Five Mortality: A Comparative Study of Egypt and Kenya
}

\author{
Mohamed A. Hussein', Margaret Mwaila² ${ }^{\text {, Doaa Helal }}{ }^{3}$ \\ ${ }^{1}$ Statistics Department, Faculty of Politics and Economics, Beni-Suef University, Beni-Suef, Egypt \\ ${ }^{2}$ National Council for Population and Development, Nairobi, Kenya \\ ${ }^{3}$ Central Agency for Public Mobilization and Statistics, Cairo, Egypt \\ Email: mmwaila001@gmail.com
}

How to cite this paper: Hussein, M.A., Mwaila, M. and Helal, D. (2021) Determinants of Under-Five Mortality: A Comparative Study of Egypt and Kenya. Open Access Library Journal, 8: e7889.

https://doi.org/10.4236/oalib.1107889

Received: August 24, 2021

Accepted: September 12, 2021

Published: September 15, 2021

Copyright $\odot 2021$ by author(s) and Open Access Library Inc.

This work is licensed under the Creative Commons Attribution International License (CC BY 4.0).

http://creativecommons.org/licenses/by/4.0/

\begin{abstract}
Introduction: Despite remarkable progress in childhood survival, sub-Saharan Africa still experiences the highest under-five mortality globally. Indeed, the risk of childhood death is 14 times higher in low income countries compared to high income countries. Egypt and Kenya are both low middle-income countries with varied under-five mortality experiences. While Egypt has reached the Sustainable Development Goal target, Kenya is still lagging behind. Objective: This study aimed to identify and compare the key determinants of under-five mortality in the context of socio-demographic and behavioural characteristics of the mother as well as demographic characteristics of the new born in Egypt and Kenya. Method: The data source for this study was the 2014 Egypt and Kenya Demographic and Health Surveys. Descriptive and inferential statistics were used for data analysis. Binary logistic regression analysis showed statistical significance of $\mathrm{p}$-value $<0.01$ for both countries. Also, the model could correctly predict $99 \%$ and $98 \%$ of cases in Egypt and Kenya respectively. Results: A total sample of 7576 and 9713 births in Egypt and Kenya, respectively was drawn from women who reported their last birth within the five years preceding the survey. Under-five mortality was reported at $1 \%$ and $2 \%$ in Egypt and Kenya respectively. In the final model, richer women in Egypt ( $\mathrm{OR}=3.375)$; older mothers 25 - 39 ( $\mathrm{OR}=1.592$ Kenya, $\mathrm{OR}$ $=1.916$ Egypt $)$; those aged $40-49(\mathrm{OR}=3.043$ Kenya, $\mathrm{OR}=5.191$ Egypt $)$; mother's higher education ( $\mathrm{OR}=0.342$ Kenya, $\mathrm{OR}=0.194$ Egypt); being female $(\mathrm{OR}=0.717$ Kenya); contraceptive use $(\mathrm{OR}=1.992$ Kenya, $\mathrm{OR}=4.241$ Egypt) showed significant association with under-five mortality compared to their counterparts. Conclusion: Under-five mortality was significantly associated with mother's age, education and contraceptive use. Educated women are best placed to use contraception to space and limit births as well as promote campaigns against risky old age childbearing thereby reducing childhood mortality.
\end{abstract}




\section{Subject Areas}

Under-Five Mortality

\section{Keywords}

Under-Five Mortality, EDHS 2014, KDHS 2014, Comparative Study, Determinants, Egypt, Kenya

\section{Introduction}

Under-five mortality refers to the probability of dying before age five-it is childhood mortality. On $20^{\text {th }}$ November 1959, the United Nations General Assembly adopted the UN Declaration of the Rights of the Child (1959), which proclaimed 10 principles of child rights. Among them were child protection, education, health care, shelter and good nutrition [1]. Remarkable progress in child survival has been made in the past few decades globally, and millions of children have better survival chances today than in 1990s. Despite the global progress, an estimated 5.3 million children aged below five died in 2018. About half of those deaths occurred in sub-Saharan Africa [2].

Global evidence points to inequities in childhood mortality. According to World Health Organization (WHO), the risk of a childhood death is still highest (76 per 1000 live births) in the WHO African Region. This is 8 times higher than that in the WHO European Region (9 per 1000 live births). Indeed, under-five mortality is 14 times higher in low-income countries compared to high-income countries [2]. Africa, especially, sub-Saharan Africa still endures the most of childhood mortalities as most governments struggle with under-funded healthcare systems. Despite the Maputo commitment to increase health budgets to at least 15 percent of each country's total budget, this commitment has fallen short in many countries, Kenya included. Yet, such financial outlay is required for the implementation of Universal Health Coverage (UHC) - a target within the Health Sustainable Development Goal (SDG) that calls on governments to ensure that all people receive the essential health services they need without being exposed to financial hardship [2]. In a study in Ghana, [3] observed low likelihood of under-five mortality among respondents with national health insurance cover.

Household poverty greatly increases the level of under-five mortality. [3] [4] [5] [6] found a significant relationship between household income, wealth index and poverty levels and child mortality. WHO recommends prioritization in reducing inequities to save and improve children's lives by ending preventable child deaths at country-levels.

The world set a new global development agenda in 2015-the Sustainable Development Goals (SDGs) to be achieved by 2030 . The proposed child mortality target aims to end preventable deaths of new-borns and children aged below five 
years. For this reason, all countries target to reduce neonatal mortality to at least as low as 12 deaths per 1000 live births and under-five mortality to at least as low as 25 deaths per 1000 live births [7].

This study compares the socio-demographic and behavioural determinants of under-five mortality in Egypt and Kenya in as far as considering the achievement of the SDG target of ending preventable child deaths by 2030.

\section{Countries Background}

This section provides some geographic, economic and demographic background information of the two countries under study, i.e. Egypt and Kenya.

The Arab Republic of Egypt is situated at the crossroads between Europe and the Orient and between North Africa and southwest Asia. Egypt controls both the Sinai Peninsula, the only land bridge between Africa and the remainder of the Eastern Hemisphere, and the Suez Canal, the shortest sea link between the Indian Ocean and the Mediterranean Sea. The Mediterranean forms the northern boundary, on the east is Israel and the Gaza strip, on the south is Sudan, and on the west is Libya. Egypt has a total area of $1,001,450 \mathrm{Km}^{2} .95$ percent of its over 100 million population lives within $20 \mathrm{Km}$ of the Nile River and delta. The country has a high population growth rate and Total Fertility Rate (TFR) plateaued at 3.6 births per women of reproductive age since 2011. Sex ratio at birth is 1.06 (more males than females) [8].

Kenya is located in the East Africa region. The country borders Tanzania and Uganda to the west, South Sudan and Ethiopia to the north, Somalia to the east and the Indian Ocean to the south. Kenya covers a total area of $580,876.3 \mathrm{Km}^{2}$ with a population density of 82 persons per $\mathrm{Km}^{2}$. According to the 2019 Population and Housing Census, Kenya's population is approximately 47.6 million with a sex ratio of 98 (more females than males). The intercensal population growth rate was reported at 2.2 percent and average household size was reported at 3.9 persons [9].

Under-five mortality country disparities can be predicated on the people's living standard which can be measured/compared using the Gross National Income (GNI) per capita measured using the Purchasing Power Parity (\$) (PPP\$). For example, according to PRB 2021 report, Egypt recorded Infant Mortality Rate (IMR) of 16/1000 live births and a GNI (PPP\$) of 12,210 while Kenya had IMR of 30/1000 live births and a GNI of only 4370. Also, countries like China and Saudi Arabia with high GNI reported very low IMR-9 and 5/1000 live births, respectively. This further confirms that wealthier countries have low child mortalities [10]. While the World Bank classification of June 2019 ranked both Egypt and Kenya as lower-middle-income economies, the two have variant under-five mortality experiences.

Egypt and Kenya have witnessed decreasing trends in under-five mortality over the years. However, the trends are distinctly different as shown in Figure 1. By 2018, Egypt's under-five mortality rate had dropped four-fold from about 


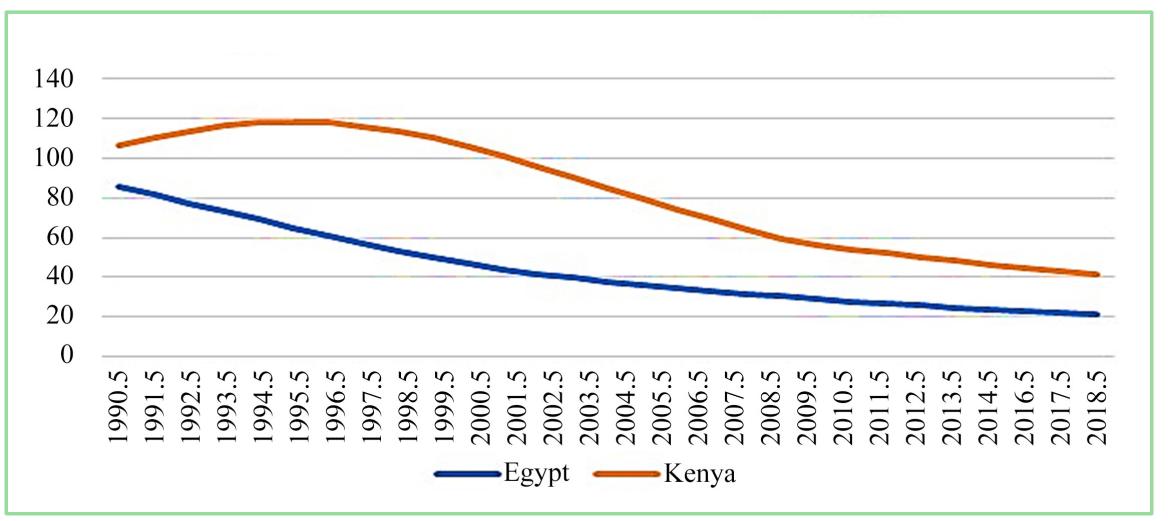

Figure 1. Trends of Under-five Mortality in Egypt and Kenya, 1990-2018. Source: Constructed using data downloaded from http://data.unicef.org.

88/1000 live births in 1990 to only 22/1000 live births. Kenya, on the other hand, experienced a surge in under-five mortality in the 1990s, peaking at almost 120/1000 live births before dropping gradually to 42/1000 live births in 2018 .

Figure 1 presents trends of under-five mortality in Egypt and Kenya from 1990 to 2018.

\section{Objective of the Study}

This study aims to identify and compare the key determinants of under-five mortality (death) in the context of socio-demographic and behavioural characteristics of the mother as well as demographic characteristics of the new born in Egypt and Kenya. Specifically, the study compared the following characteristics of women who reported having their last birth in the five-year period before the survey: Age, place of residence, region of residence, marital status, level of education, wealth index, number of under-five children in the household and current use of contraception (as a behavioural characteristic). For the newborn, the study considered sex of the child.

\section{Data Source}

Egypt's 2014 Demographic and Health Survey (EDHS) [11] is the tenth in a series of demographic and health surveys conducted in Egypt. The 2014 EDHS sample was designed for six main subdivisions (urban, rural, Lower Egypt, Lower Egypt countryside, rural Egypt, Rural Egypt, Rural Upper Egypt, and border governorates). 29,471 households were included in the survey sample. Egypt now has nearly thirty years of data documenting its progress in improving the health of women and children, including child mortality, vaccination coverage, nutritional status, and maternal health care.

Kenya's 2014 Demographic and Health Survey (KDHS) [12] was implemented by the Kenya National Bureau of Statistics from May 2014 to October 2014 in partnership with other governmental and international partner organizations. Given that the country's governance system had just been devolved, the 2014 
KDHS sought wider coverage in terms of sample size and content. 36,430 households were interviewed with a response rate of 99 percent.

This study will depend on data from the demographic and health surveys of 2014 in Kenya and Egypt. The main interest of this study is the mortality of children below five years experienced by women who reported having their last birth within the five-year period preceding the surveys. The study sample for Egypt comprises 7576 births with an accompanying 93 under-five deaths while Kenya's sample is 9713 births with 240 childhood deaths, respectively.

\section{Literature Review}

Under-five mortality (U5M) is a key indicator of child health as well as the socio-economic status of any country. According to UNICEF [13], 85 percent of child deaths occur during the first five years of life. Further, it is estimated that 52 million children under five years will die during the period 2019 and 2030.

Being an important indicator, under-five mortality has been extensively studied globally. This section presents some studies on under-five mortality conducted within Egypt, Kenya as well as in other countries each highlighting the key determinants of childhood deaths.

\subsection{Egypt}

A study by [4] examined the determinants of infant and child mortality in rural Egypt. The specific focus of the study was on the effects of household economic status and the availability of health services on child mortality. A sample of 2783 ever married women was picked from the 1980 Egyptian Fertility Survey which was part of the World Fertility Survey. The study used cross-tabulations and chi-square tests to analyze relationships between predictor variables and child mortality. The results showed that household sanitation, maternal risk factors, socio-economic factors or skilled services were not responsible for differences in child mortality between Upper (higher mortality) and Lower Egypt (lower mortality). In addition, maternal age, number of births (parity), preceding birth interval and region were significant predictors at neonatal stage but region waned off at early childhood. Household income, especially from employment, was significant for early childhood survival. However, parents' education did not have much impact on child survival.

In examining the importance of prenatal care and maternal education on infant mortality in Egypt, [14] specifically sought to demonstrate the efficiency with which birth history data and log probability models can be used to estimate the odds of dying in the first year of life. The study obtained birth history data for 11,500 births that occurred during the five-year period prior to the 2000 Egypt Demographic and Health Survey (EDHS). The analysis was three-fold. Stage one involved the log probability models to estimate deaths at infancy and under-five years. Stage two used generalized linear models to examine bivariate relationships between infant mortality and determinants such as prenatal care, 
maternal education, birth order, sex of child and place of residence. The last stage used the multivariate model. The study found that maternal education reduces the odds of infant deaths. However, prenatal care remained significant at the multivariate analysis stage.

A cross-sectional study and follow-up assessment of the morbidity and mortality of low birth weight infants during the first 3 months of life was done in Egypt between 1995 and 1997 [15]. The study sample was 6701 live births. However, multiple births were excluded leaving a sample of 6398 singleton live births. Using a structured questionnaire, administered to mothers whose babies were admitted at the Neonatal Intensive Care Unit, data was collected on sociodemographic, maternal and delivery including the new-born characteristics. Chi-square tests were conducted to assess the significance of predictor variables on neonatal mortality. Multiple logistic regression analysis was used to control for potential confounding factors, such as: place of residence, maternal age, maternal education, paternal education, maternal work, crowding index, place of delivery, sex of new-born, parity and spacing. The study found that babies with low birth weight suffered higher mortality compared to babies with normal birth weight.

[16] examined the socio-economic and bio-demographic determinants of neonatal, post neonatal and infant mortality in Egypt using the 2005 Egypt Demographic and Health Survey (EDHS). The sample comprised 13,851 live births. The study used logistic regression analysis for the neonatal period while Cox proportional hazard model was used to determine significance of factors of infant and post neonatal mortality. The results revealed strong association between infant mortality and bio-demographic factors. However, the only significant socioeconomic determinant was educational attainment of the mother. In addition, the study found that mother's education, child's sex and place of delivery were time-dependent covariates after adjusting for all socio-economic and bio-demographic factors. At neonatal stage, child's sex and place of delivery were significant predictors of neonatal mortality. Furthermore, taking the three into consideration, the study concluded that the risk of neonatal, post-neonatal and infant death was consistently related to birth interval and birth size.

[17] conducted a cross-sectional study on the "at risk" under-five children attending the Rasheed Family Health Centre in Egypt. The study had two objectives, namely: to determine prevalence and identify determinants of "at risk" children below five years and determine pattern of utilization of available health services at the Centre. The study sample comprised 300 under-fives and their mothers. Data was collected using a questionnaire and analysed using multiple regression model. The results showed, among others, that crowding, infections of the respiratory tract, birth spacing and breastfeeding were significant predictors for "at risk" children under five years of age.

[18] explored the association between the demographic, perinatal care and socio-economic factors and neonatal mortality in the Eastern Mediterranean Re- 
gion (EMR). The study covered eleven EMR countries, namely Egypt, Bahrain, Lebanon, Oman, Tunisia, Iran, Saudi Arabia, Libya, Morocco, Qatar and Syria. The study used secondary data collected between 1990 and 2013 from official UN websites (WHO, UNICEF, UNESCO). The 1990 data was however, only used for trend analysis in terms of observed declines in neonatal mortality. The correlation coefficient methodology (Spearman Rank Coefficient Analysis) was used to draw associations between the outcome variable (neonatal mortality) and explanatory variables. The study results (among others) showed that there was a negative but significant association between neonatal mortality and literacy status of both men and women. In addition, significant positive correlation was noted between low birth weight and neonate death. Educated mothers were more likely to seek skilled care and delivery and babies delivered by skilled attendants had better chances of survival.

[19] conducted a study between 1992 and 1996 aimed at determining indices, leading causes and socio-demographic factors of childhood mortality in six sites in rural Upper Egypt. Verbal autopsy was used with mothers and caretakers who reported a death of a child aged below five. The case group comprised 214 reported under-five mortalities. Additional information was obtained from 1025 living children who were below five years (control group). The study used multivariate logistic regression model to analyze the data. The study found that the leading causes of death were predicated on natal and neonatal complications. The results also revealed that diarrhoeal diseases and acute respiratory infections were leading cause of death as indicated by the verbal autopsy. On the other hand, age of the child and mother's age at childbirth were found to be the strongest predictors of childhood mortality. In addition, parental illiteracy, parental age differences, house ownership, birth order and average meat consumption at the household were also key determinants.

\subsection{Kenya}

[5] conducted a study to investigate geographical location and maternal factors' influence on the likelihood of under-five mortality in rural and urban areas in Kenya. The study used a sample of 16,162 births that had been reported in the five years preceding the 2008-2009 Kenya Demographic and Health Survey (KDHS). Multivariate analysis was used to compare crucial risk factors in both urban and rural populations. The study found that rural areas had higher under-five mortality especially due to high poverty levels. Moreover, the influence of breastfeeding was significant in both rural and urban mortality cases.

[20] investigated the determinants of neonatal and under-five mortality in Kenya with the objective of examining the effect of antenatal and skilled delivery care services on under-five and neonatal mortality. The study used data from the 1998, 2003 and 2008-2009 Kenya Demographic and Health Surveys (KDHS) using a sample of 36,523 births that happened within five years prior to each survey. The study used descriptive statistics, chi-square tests and the $\mathrm{Z}$ statistics. The study results showed that skilled deliveries were associated with low risk of 
neonatal and under-five deaths while tertiary education level of the mother was not significantly associated to risk of neonate death. However, the association was significant for under-five mortality. In addition, the study found that risk of under-five mortality reduced with age of mother but male children had a higher risk of death at both neonatal and under-five.

[21] undertook a study to analyze and compare factors associated with under-five mortality in Kenya's urban and rural residences. Using data from the 2014 Kenya Demographic and Health Survey (KDHS), the study sample comprised 20,964 births reported in the five years preceding the survey. This study used descriptive and survival parametric analyses to compute rural-urban under-five mortality differentials and identify associations between key predictor variables and under-five mortality. The results showed that children born to older women (aged 35 and above) had higher risk of dying before their fifth birthday. Source of drinking water, birth order, preceding birth interval, type of toilet, region, maternal education, religion, wealth index and mother's employment status were all significant predictors of under-five mortality.

In a study to establish the effect of region of residence on neonatal and post-neonatal mortality in Kenya, [22] used the 2003 Kenya Demographic and Health Survey data where 5949 live births were reported by women of reproductive age within a five-year period preceding the survey. The study used log-log plots and scaled Schoenfeld residuals to test for violation of the proportionality assumption. No evidence of violation was found. The study used Cox proportional hazard regression with stepwise model fitting. The results showed that children born to women with at least secondary education had a significantly lower neonatal mortality risk. Likewise, maternal age at birth, baby size at birth and the preceding birth interval had a significant net effect on neonatal mortality. Finally, public health facility deliveries had higher neonatal mortality risk compared to home deliveries. However, place of residence (rural/urban) had no significant effect on neonatal mortality.

[23] conducted a cross sectional study of the determinants of under-five mortality among pastoralist communities of Kajiado County in Kenya. The study used both qualitative and quantitative methods. Using the cluster and random sampling methods, the study identified 384 households out of 2953 in the sampling frame. The study used a structured questionnaire to collect information about 1563 births reported in the five years prior to the study. Data was analyzed using SPSS V20. Specifically, the study used descriptive statistics to come up with frequencies, percentages and chi-square test results. The results showed that the most significant determinants of the under-five mortality were mother's education, age at first birth and low immunization coverage. Marital status and type of marriage (monogamy or polygamy) were not found to be significant.

\subsection{Other Countries}

Using data from the 2007 Bangladesh Demographic and Health Survey [24] ex- 
amined determinants of under-five mortality in Bangladesh. The study used a sample of 4003 births which was considered sufficient for analyzing child mortality. The study used Chi-square test for independence and multivariate proportional hazard analyses. The results showed that father's education, place of residence, region of residence, number of children under five years of age, previous death of sibling, mother's age and breastfeeding have significant influence on under-five mortality. Households with two or more under-five children had higher under-five mortality compared to those with one under-five child. In addition, ever use of contraception was found to be a strong predictor for under-five mortality. The proximate determinants such as demographic, environmental, nutritional and health seeking behavioural factors were found to have stronger influence on under-five mortality than the socioeconomic factors.

In a study to analyze trends as well as investigate differentials and key proximate determinants of infant and under-five mortality in Ethiopia, [25] used DHS data of 2000, 2005 and 2011. The sample comprised 32,388 births (31,618 single births and 770 multiple births) reported in the five years preceding the surveys. Using Cox regression analyses, the study concluded sex of the child, birth size, birth interval, mother's education and mother's marital status and access to improved toilet facilities were significant determinants of infant and childhood mortality. Region of residence was also a significant predictor variable for both infant and under-five mortality.

[26] analyzed trends related to mother's education and under-five mortality in sub-Saharan Africa between 1990 and 2015. Countries included in the sample were Burkina Faso, Niger, Guinea, Cameroon, Congo, Malawi, Zambia and Namibia. Using different waves of Demographic and Health Surveys of the sampled countries, the study worked with 213,804 births. Logistic regression and Buis's decomposition methods were used to explore effects of mother's education on deaths of children below five years. The study observed that mothers with no education reported higher under-five mortality rates compared to those with formal education. However, the results showed more rapid reduction in mortality of children under five whose mothers had no education compared to those whose mothers were educated. In addition, birth order, maternal age during childbirth, the birth interval, multiple births, the child's sex, and place of residence were significantly associated with the mortality of children aged below five.

[6] conducted a study to investigate the relationship between the socio-economic status of the household and under-five mortality, measure health inequality as well as define risk factors associated with under-five mortality at Rufiji Demographic Surveillance Site (RDSS) in Tanzania. The analytical cross-sectional study used a sample of 11,189 children below five years in 2005. Principal component analysis was used to construct household socio-economic status. Kaplan Meier survival incidence estimates were used to analyze mortality rates. Health inequality was measured by calculating and comparing mortality rates between the poorest and least poor wealth quintile. A mortality concentration index was 
also computed and Poisson regression used to assess child mortality risk factors. The study found that children below five years from poorest households were 2.4 times more likely to die than those from least poor. Moreover, there was a 70 percent reduced risk of death among children whose mothers had secondary education compared to those with no education.

[3] conducted a study to explore the association between socio-economic and demographic factors and under-five mortality in an impoverished region in rural northern Ghana. The study used data from a cross-sectional baseline survey of the Ghana Essential Health Intervention Project (GEHIP) conducted in 2011. The study sample comprised of data on 3975 women of reproductive age who have ever given birth. Chi-square test was used to test the association of social, economic and demographic characteristics of mothers with the experience of under-five death. The study used logistic regression model to estimate the relative association of factors that influence childhood mortality after excluding variables that were not significant at the bivariate level. The results showed that mothers' educational level, presence of co-wives, age and marital status significantly predicted under-five mortality. In addition, mothers aged 35 to 49 were more likely to experience under-five deaths than those below 20 years while single, divorced or widowed women had higher chances of losing a child below age five than married women. Further, women who were using contraception were less likely to experience under-five deaths compared to non-users.

[27] used the 2016 Ethiopia DHS data to identify survival status and determine the proximate determinants of infant mortality in Ethiopia. The study used a sample of 10,641 live births and also reviewed survival information of all the 2826 infants born within five years prior to the survey. Using Kaplan-Meier estimation, the study found that 65 percent of infant deaths occurred in the "first month of life" (neonate period). The Cox Proportional Hazard Model placed mother's education, age, place of residence, preceding birth interval, place of delivery, wealth index, size of child at birth and sex of child as significant predictors of infant mortality.

[28] undertook a study to examine factors associated with infant and child mortality in Saudi Arabia using the 1987 Saudi National Child Health Survey data. The study sample was made up of 13,300 children below five years of age. Data was analysed using multivariate analysis. The results revealed high mortality cases among rural and southern regions compared to urban and eastern regions. Mother's age, number of previous births, skilled care and delivery and diarrhoea care were significant predictors of under-five mortality. The multivariate regression analysis confirmed the effect of parents' education, father's occupation, source of drinking water and place of defecation on both infant and child mortality.

\section{Methodology}

This study used two data analysis methodologies. 
First, descriptive techniques have been used to examine the levels and differentials of under-five mortality both in Kenya and in Egypt. In addition, background characteristics of women who had a last birth within the five-year period before the surveys were also investigated on the backdrop of under-five mortality. In descriptive analysis, Chi-square tests were used to test for existence of association between categorical variables, i.e. the dependent variable (child death) and some socio-demographic and behavioral indicators (independent) that determine childhood mortality.

The second technique was inference analysis. Given that this study has a categorical response variable with only two possible outcomes (child alive/child dead), binary logistic regression model was used. The technique is useful in modelling the relationship between predictor variables and a categorical response variable. While predicting the significance of the regression model, binary logistic regression is crucial in describing the relationships between the socio-demographic and behavioural determinants and under-five mortality. It is worth mentioning that all predictor variables in this study are also categorical.

The multiple binary logistic regression equation is:

$$
P(Y)=\exp \left(\beta_{0}+\beta_{1} X_{1}+\beta_{2} X_{2} \ldots+\beta_{n} X_{n}\right) /\left(1+\exp \left(\beta_{0}+\beta_{1} X_{1}+\beta_{2} X_{2} \ldots+\beta_{n} X_{n}\right) .\right.
$$

where:

$$
\begin{aligned}
& P=\text { Probability of a success } \\
& Y=\text { Dependent variable } \\
& \beta_{0}=\text { Constant } \\
& \beta_{n}=\text { Coefficients of variables } X_{1} \ldots X_{n} \\
& X_{n}=\text { Independent variables } X_{1} \ldots X_{n}
\end{aligned}
$$

The model describes the probability of an event happening as a function of independent variables. In this study, it could be the probability of an under-five mortality given, for example, the age of the mother.

As in any logistic model, the above equation predicts the probability of an event $(Y)$ occurring when coefficients Beta and $\mathrm{X}$ variables are fitted on the binary regression model. The probability of an event occurring is always between 0 and 1 . This is because the numerator $-\exp \left(\beta_{0}+\beta_{1} X_{1}+\beta_{2} X_{2} \ldots+\beta_{n} X_{n}\right)$ must be positive, given that it is a power of a positive value $(e)$ and the denominator of the model is ( $1+$ numerator), the answer will always be less than 1 [29].

The outcome variable and all the explanatory variables were fitted on the binary regression model to estimate the relationship, significance and probabilities of childhood deaths.

\section{Results}

This section will discuss results of the descriptive and binary logistic regression analyses. The descriptive analysis comprised of cross-tabulations and chi-square tests conducted on background characteristics and covariates of under-five mortality. In the multiple binary logistic regression model, the dependent variable (child death) was fitted against all the predictor variables. 


\subsection{Background Characteristics}

Table 1 presents the percentage distribution of some background characteristics of women whose last birth occurred within the five-year period preceding both the 2014 Egypt Demographic and Health Survey (EDHS) and the 2014 Kenya Demographic and Health Survey (KDHS).

Table 1 shows that about half (51 percent) of the women in Egypt and 56 percent of their counterparts in Kenya who reported having a last birth during the study period were under 30 years of age. More than 60 percent of the births in the two countries were reported by women aged 25 - 39. In addition, majority of the women were living in rural areas- 57 percent in Egypt and 62 percent in Kenya, respectively.

In terms of regional distribution, majority of births were reported in Rural Lower Egypt (28 percent). On the other hand, Rift Valley in Kenya reported majority of births (30 percent). Frontier governorates (6 percent) in Egypt and North Eastern (4 percent) and Nairobi (3 percent) in Kenya reported the lowest births.

Women with higher education in Egypt reported one percentage point higher births (17 percent) compared with those who never attended school (16 percent). Considering educational attainments of women who reported births, the study observed an interesting trend. Women with secondary level of education reported approximately three in five births (58 percent) in Egypt, while more than half of births (52 percent) in Kenya occurred among women with primary education.

In addition, Table 1 also displays another inverse relationship between the two countries in terms of reported births by wealth quintiles. Women in the rich quintile in Egypt reported 45 percent of births, while women in the poor quintile in Kenya reported 43 percent of births. Almost all births in Egypt, were reported by married women (98 percent). In Kenya, about one in five births occurred among women who were not in union (not married, widowed, divorced or separated).

Table 1. Percent Distribution of Women whose last birth was during the five-year period preceding the surveys by some of their Background Characteristics, Egypt and Kenya, 2014.

\begin{tabular}{ccccc}
\hline \multirow{2}{*}{ Description } & \multicolumn{2}{c}{ Egypt } & \multicolumn{3}{c}{ Kenya } \\
\cline { 2 - 5 } & $\%$ & $\mathrm{~N}$ & $\%$ & $\mathrm{~N}$ \\
\hline & Current Age & & \\
\hline $15-19$ & 3.6 & 269 & 7.6 & 741 \\
$20-24$ & 18.6 & 1411 & 21.3 & 2069 \\
$25-29$ & 29.2 & 2209 & 26.7 & 2592 \\
$30-34$ & 25.8 & 1952 & 19.9 & 1929 \\
$35-39$ & 15.7 & 1191 & 14.4 & 1400 \\
\hline
\end{tabular}




\section{Continued}

\begin{tabular}{|c|c|c|c|c|}
\hline $40-44$ & 6.1 & 463 & 7.7 & 745 \\
\hline $45-49$ & 1.0 & 81 & 2.4 & 237 \\
\hline \multicolumn{5}{|c|}{ Place of Residence } \\
\hline Urban & 43.2 & 3273 & 38.0 & 3692 \\
\hline Rural & 56.8 & 4303 & 62.0 & 6021 \\
\hline \multicolumn{5}{|c|}{ Region } \\
\hline Coast & ---- & ---- & 12.0 & 1166 \\
\hline North Eastern & ---- & ---- & 4.1 & 394 \\
\hline Eastern & ---- & ---- & 17.0 & 1647 \\
\hline Central & ----- & ---- & 10.2 & 987 \\
\hline Rift Valley & ----- & ---- & 30.3 & 2939 \\
\hline Western & ---- & ---- & 9.2 & 889 \\
\hline Nyanza & ---- & ---- & 14.0 & 1358 \\
\hline Nairobi & ----- & ---- & 3.4 & 333 \\
\hline Urban governorates & 16.2 & 1228 & ----- & ----- \\
\hline Urban Lower Egypt & 10.7 & 814 & ----- & ----- \\
\hline Rural Lower Egypt & 27.9 & 2118 & ----- & ---- \\
\hline Urban Upper Egypt & 12.2 & 930 & ----- & ---- \\
\hline Rural Upper Egypt & 26.9 & 2038 & ----- & ---- \\
\hline Frontier governorates & 5.9 & 448 & ---- & ----- \\
\hline \multicolumn{5}{|c|}{ Highest Level of Education } \\
\hline No Education & 15.6 & 1253 & 13.3 & 1291 \\
\hline Primary & 9 & 671 & 51.7 & 5024 \\
\hline Secondary & 57.7 & 4373 & 25.6 & 2489 \\
\hline Higher & 16.8 & 1279 & 9.4 & 909 \\
\hline \multicolumn{5}{|c|}{ Wealth Index } \\
\hline Poorest & 16.9 & 1286 & 23.3 & 2260 \\
\hline Poorer & 17.5 & 1333 & 19.6 & 1905 \\
\hline Middle & 19.9 & 1510 & 19.1 & 1859 \\
\hline Richer & 22.0 & 1670 & 19.3 & 1870 \\
\hline Richest & 23.4 & 1777 & 18.7 & 1819 \\
\hline \multicolumn{5}{|c|}{ Marital Status } \\
\hline Not Married & 0.5 & 39 & 10.6 & 1032 \\
\hline Married & 97.7 & 7403 & 78.5 & 7622 \\
\hline Other (Widowed/Divorced/Separated) & 1.7 & 134 & 10.9 & 1059 \\
\hline Total & 100 & 7576 & 100 & 9713 \\
\hline
\end{tabular}

Source: Generated from 2014 Egypt and Kenya DHS datasets. 


\subsection{Under-Five Mortality and Its Correlates in Egypt and Kenya}

Figure 2 presents the under-five mortality experiences of women in Egypt and Kenya. Of the 7576 births reported in Egypt during the survey period, child survival was high at almost 99 percent while in Kenya, 9713 births were reported with a survival rate of almost 98 percent. Under-five mortality was 1 percent in Egypt and 2 percent in Kenya.

Research has provided insurmountable evidence with regard to factors that may lead to deaths of children below five years. The framework provided by Mosley and Chen [30] on proximate determinants of child survival has remained plausible for both social and health scientists. Table 2 shows some socio-demographic and environmental factors that determine under-five mortality that this study considered.

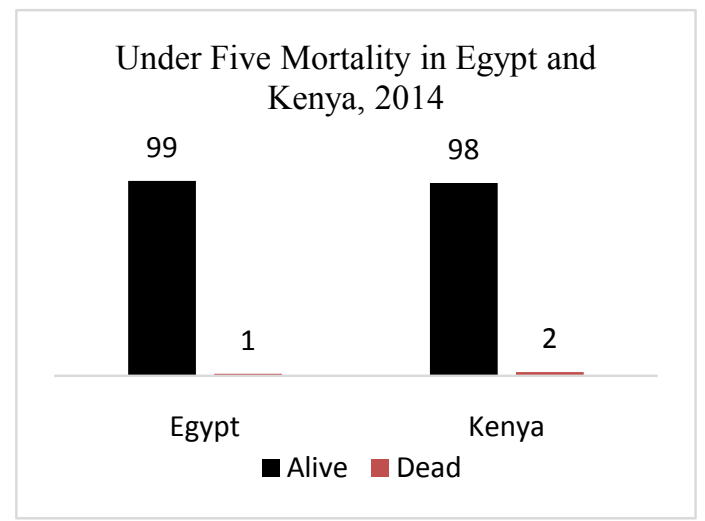

Figure 2. Percent Distribution of last births according to under-five mortality in Egypt and Kenya, 2014. Source: Generated from 2014 Egypt and Kenya DHS datasets.

Table 2. Percent distribution of under-five mortality by some background and sociodemographic characteristics, 2014 Demographic and Health Surveys, Egypt and Kenya.

\begin{tabular}{ccccccccc}
\hline \multirow{2}{*}{ Items } & \multicolumn{3}{c}{ U5M in Egypt } & \multicolumn{5}{c}{ U5M in Kenya } \\
\cline { 2 - 9 } & \% Dead & \% Alive & Total \% & N & \% Dead & \% Alive & Total \% & N \\
\hline Urban & 0.8 & 99.2 & 100 & 3273 & 2.6 & 97.4 & 100 & 3692 \\
Rural & 1.6 & 98.4 & 100 & 4303 & 2.4 & 97.6 & 100 & 6021 \\
\hline & & & Region & & & & & \\
\hline Coast & ----- & ----- & ----- & ---- & 3.1 & 96.9 & 100 & 1166 \\
North Eastern & ----- & ----- & ----- & ----- & 2.3 & 97.7 & 100 & 394 \\
Eastern & ----- & ----- & ----- & ----- & 1.8 & 98.2 & 100 & 1647 \\
Central & ----- & ----- & ----- & ----- & 2.1 & 97.9 & 100 & 987 \\
Rift Valley & ----- & ----- & ----- & ----- & 2.1 & 97.9 & 100 & 2939 \\
Western & ----- & ----- & ----- & ----- & 2.8 & 97.2 & 100 & 889 \\
Nyanza & ----- & ----- & ---- & ----- & 3.5 & 96.5 & 100 & 1358 \\
Nairobi & ----- & ----- & ----- & ----- & 2.7 & 97.3 & 100 & 333 \\
Urban governorates & 0.7 & 99.3 & 100 & 1228 & ----- & ----- & ----- & ---- \\
\hline
\end{tabular}




\section{Continued}

\begin{tabular}{|c|c|c|c|c|c|c|c|c|}
\hline Urban Lower Egypt & 1.0 & 99.0 & 100 & 814 & ---- & ---- & ---- & ----- \\
\hline Rural Lower Egypt & 1.2 & 98.8 & 100 & 2118 & ----- & ----- & ----- & ----- \\
\hline Urban Upper Egypt & 0.8 & 99.2 & 100 & 930 & ----- & ----- & ---- & ----- \\
\hline Rural Upper Egypt & 2.0 & 98.0 & 100 & 2038 & ---- & ---- & ---- & ----- \\
\hline Frontier governorates & 0.7 & 99.3 & 100 & 448 & ----- & ----- & ----- & ----- \\
\hline \multicolumn{9}{|c|}{ Current Age } \\
\hline $15-19$ & 2.2 & 97.8 & 100 & 269 & 1.9 & 98.1 & 100 & 741 \\
\hline $20-24$ & 1.1 & 98.9 & 100 & 1411 & 2.6 & 97.4 & 100 & 2069 \\
\hline $25-29$ & 1.2 & 98.8 & 100 & 2209 & 1.6 & 98.4 & 100 & 2592 \\
\hline $30-34$ & 1.1 & 98.9 & 100 & 1952 & 2.4 & 97.6 & 100 & 1929 \\
\hline $35-39$ & 1.3 & 98.7 & 100 & 1191 & 3.0 & 97.0 & 100 & 1400 \\
\hline $40-44$ & 1.7 & 98.3 & 100 & 463 & 3.8 & 96.2 & 100 & 745 \\
\hline $45-49$ & 1.2 & 98.8 & 100 & 81 & 5.5 & 94.5 & 100 & 237 \\
\hline \multicolumn{9}{|c|}{ Highest Educational Leve ${ }^{*}$} \\
\hline No education & 1.8 & 98.2 & 100 & 1253 & 2.3 & 97.7 & 100 & 1291 \\
\hline Primary & 1.0 & 99.0 & 100 & 671 & 2.9 & 97.1 & 100 & 5024 \\
\hline Secondary & 1.2 & 98.8 & 100 & 4373 & 2.1 & 97.9 & 100 & 2489 \\
\hline Higher & 0.8 & 99.2 & 100 & 1279 & 1.2 & 98.8 & 100 & 909 \\
\hline \multicolumn{9}{|c|}{ Wealth Index ${ }^{* *}$} \\
\hline Poorest & 1.9 & 98.1 & 100 & 1286 & 2.6 & 97.4 & 100 & 2260 \\
\hline Poorer & 1.3 & 98.7 & 100 & 1333 & 2.7 & 97.3 & 100 & 1905 \\
\hline Middle & 1.4 & 98.6 & 100 & 1510 & 2.8 & 97.2 & 100 & 1859 \\
\hline Richer & 1.3 & 98.7 & 100 & 1670 & 2.2 & 97.8 & 100 & 1870 \\
\hline Richest & 0.6 & 99.4 & 100 & 1777 & 2.0 & 98.0 & 100 & 1819 \\
\hline \multicolumn{9}{|c|}{ Number of Under 5 children in the Household ${ }^{*}$} \\
\hline 0 (None) & 16.5 & 83.5 & 100 & 424 & 30.9 & 69.1 & 100 & 580 \\
\hline 1 (one) & 0.3 & 99.7 & 100 & 5581 & 0.8 & 99.2 & 100 & 6859 \\
\hline $2-5$ & 0.2 & 99.8 & 100 & 1550 & 0.4 & 99.6 & 100 & 2271 \\
\hline 6 or more & - & 100 & 100 & 21 & 0.0 & 100 & 100 & 3 \\
\hline \multicolumn{9}{|c|}{ Current Contraceptive use } \\
\hline Not Using & 2.4 & 97.6 & 100 & 3053 & 3.5 & 96.5 & 100 & 4368 \\
\hline Using & 0.4 & 99.6 & 100 & 4523 & 1.6 & 98.4 & 100 & 5345 \\
\hline \multicolumn{9}{|c|}{ Marital Status* } \\
\hline Not Married & 5.1 & 94.9 & 100 & 39 & 2.1 & 97.9 & 100 & 1032 \\
\hline Married & 1.2 & 98.8 & 100 & 7403 & 2.4 & 97.6 & 100 & 7622 \\
\hline Other (Wid/Div/Sep) & 2.9 & 97.0 & 100 & 134 & 3.5 & 96.5 & 100 & 1059 \\
\hline \multicolumn{9}{|c|}{ Sex of Child } \\
\hline Male & 1.2 & 98.8 & 100 & 4049 & 2.6 & 97.4 & 100 & 4959 \\
\hline Female & 1.2 & 98.8 & 100 & 3527 & 2.3 & 97.7 & 100 & 4754 \\
\hline Total & ----- & ----- & 100 & 7576 & ----- & ----- & 100 & 9713 \\
\hline
\end{tabular}

${ }^{*}$ Significance level $\leq 0.01{ }^{*}$ Significance level $\leq 0.05$. Source: Generated from 2014 Egypt and Kenya DHS datasets. 
Table 2 presents the percent distribution of under-five mortality by some background characteristics of women who had their last birth within five years prior to the 2014 demographic and health surveys in Egypt and Kenya. The study found significant association between place of residence and under-five mortality in Egypt but not in Kenya. Furthermore, rural areas of Egypt reported double rates of mortality ( 1.6 percent) compared to urban rates of 0.8 percent.

Table 2 also shows there was a significant relationship between region and under-five mortality in Egypt but not in Kenya. The study found that the Frontier governorates in Egypt reported the least under-five mortality ( 0.7 percent) while rural Upper Egypt reported 2 percent deaths.

The data showed that age of mother and under-five mortality had a statistically significant association in Kenya while this was converse for Egypt. Children born to older women in Kenya were thrice as likely to die as those born of younger women (6 percent childhood deaths for women of 45 - 49 compared with 2 percent among women aged 15 - 19).

While educational attainment was a significant predictor for child death in Kenya, it was not for Egypt. This result is consistent with the observation that three-quarters (75 percent) of births in Egypt were reported by women with secondary and higher education while in Kenya, majority of births were among women with primary education (52 percent). The data indicates that children of women with lower education were twice as likely to die as those of women with higher education in Kenya. Women with primary education reported the highest childhood mortality ( 3 percent) in the country.

Wealth index was a significant predictor for under-five mortality in Egypt but not in Kenya. This compares well with the result of higher births reported among wealthier women in Egypt (45 percent). Rich women in Egypt reported fewer ( 0.6 percent) under-five mortality compared to their poor counterparts.

This study found that the number of under-five children in the household was a significant predictor of under-five mortality in both countries. However, both countries reported higher percent mortalities of children in households that had no under-five children (17 percent in Egypt and 31 percent in Kenya) while households with six or more children reported negligible mortality percentages.

There was a positive correlation between contraceptive use and child survival. In Egypt, women who were using any form of modern contraceptive were six times more unlikely to lose their children in childhood compared with those not using contraception. In Kenya, the difference was more than double (1.6 and 3.5 percent) between users and non-users. Contraceptive use was significantly associated with under-five mortality in both countries.

Marital status had a statistically significant relationship with under-five mortality in Egypt but not in Kenya. In Egypt, children born to unmarried, divorced, widowed or separated women were five times likely to die before their fifth birthday compared to those born of married women. Sex of the child was not a significant predictor variable for childhood mortality in the two countries. 


\subsection{Determinants of Under-Five Mortality}

As earlier stated, logistic regression helps estimate the probability of an event happening (success). It is also useful in modelling the relationship between predictor variables and a categorical response variable. Since the dependent variable is binary (alive or dead), binary logistic regression has been used in this study to model the relationship between some socio-demographic and behavioural determinants and under-five mortality in Kenya and Egypt.

In order to tease out the most significant determinants of under-five mortality, all variables (maternal background characteristics, behavioural and some child characteristics) were fitted into the logistic regression model. The results showed that the model was significant at less than 0.01 level according to the model chi-square statistic in both countries. Further, the model could correctly predict 99 percent of cases in Egypt and 98 percent of the cases in Kenya, respectively.

Table 3 presents the results of the determinants of under-five mortality as per the study objectives.

According to Table 3, mother's age had a positive and significant impact on childhood deaths in both countries after considering the effect of other independent variables. Every year increase in age among women in the 25 - 39 age cohort increased the odds of under-five mortality by 1.6 in Kenya and 1.9 in Egypt compared to those who were 15 - 24 years. While the odds of under-five mortality tripled for women aged 40 - 49 in Kenya, they quintupled among women of the same age group in Egypt relative to younger women of $15-24$ years.

Table 3. Determinants of under-five mortality by socio-demographic and background characteristics of women who had a last birth in the five-year period before the $2014 \mathrm{De}$ mographic and Health Surveys, Egypt and Kenya.

\begin{tabular}{|c|c|c|c|c|c|c|}
\hline \multirow{2}{*}{$\begin{array}{l}\text { Country } \\
\text { Variable }\end{array}$} & \multicolumn{3}{|c|}{ Kenya } & \multicolumn{3}{|c|}{ Egypt } \\
\hline & B & S.E. & Odds Ratio & B & S.E. & Odds Ratio \\
\hline \multicolumn{7}{|c|}{ Region } \\
\hline \multicolumn{7}{|c|}{ Coast (ref) } \\
\hline North Eastern & -0.489 & 0.477 & 0.613 & $\ldots \ldots$ & $\ldots \ldots$ & ..... \\
\hline Eastern & -0.164 & 0.298 & 0.849 & $\ldots \ldots$ & $\ldots \ldots$ & ..... \\
\hline Central & 0.280 & 0.339 & 1.323 & $\ldots \ldots$ & $\ldots \ldots$ & $\ldots \ldots$ \\
\hline Rift Valley & -0.126 & 0.253 & 0.882 & $\ldots \ldots$ & $\ldots \ldots$ & $\ldots \ldots$ \\
\hline Western & 0.013 & 0.323 & 1.013 & $\ldots \ldots$ & $\ldots \ldots$ & $\ldots \ldots$ \\
\hline Nyanza & 0.458 & 0.282 & 1.580 & $\ldots \ldots$ & $\ldots \ldots$ & $\ldots \ldots$ \\
\hline Nairobi & -0.047 & 0.442 & 0.954 & $\ldots \ldots$ & $\ldots \ldots$ & $\ldots \ldots$ \\
\hline \multicolumn{7}{|c|}{ Urban Governorates (ref) } \\
\hline Urban Lower Egypt & $\ldots \ldots$ & $\cdots \cdots$ & $\ldots \ldots$ & 0.285 & 0.535 & 1.329 \\
\hline Rural Lower Egypt & $\ldots \ldots$ & $\ldots \ldots$ & $\ldots \ldots$ & -0.609 & 1.238 & 0.544 \\
\hline
\end{tabular}




\section{Continued}

\begin{tabular}{|c|c|c|c|c|c|c|}
\hline Urban Upper Egypt & $\ldots \ldots$ & $\ldots \ldots$ & $\ldots \ldots$ & 0.099 & 0.577 & 1.104 \\
\hline Rural Upper Egypt & $\ldots \ldots$ & $\ldots \ldots$ & $\ldots \ldots$ & -0.061 & 1.230 & 0.940 \\
\hline Frontier governorates & $\ldots \ldots$ & $\ldots \ldots$ & $\ldots \ldots$ & -0.305 & 0.988 & 0.737 \\
\hline \multicolumn{7}{|c|}{ Place of Residence } \\
\hline \multicolumn{7}{|c|}{ Urban (ref) } \\
\hline Rural & 0.121 & 0.183 & 1.129 & 1.618 & 1.200 & 5.044 \\
\hline \multicolumn{7}{|c|}{ Wealth Index } \\
\hline \multicolumn{7}{|c|}{ Poorest (ref) } \\
\hline Poorer & 0.111 & 0.260 & 1.117 & -0.325 & 0.364 & 0.723 \\
\hline Middle & -0.209 & 0.263 & 0.812 & 0.591 & 0.385 & 1.805 \\
\hline Richer & -0.556 & 0.287 & 0.574 & 1.216 & 0.470 & $3.375^{\star}$ \\
\hline Richest & -0.444 & 0.313 & 0.641 & 0.520 & 0.642 & 1.682 \\
\hline \multicolumn{7}{|c|}{ Current Age } \\
\hline \multicolumn{6}{|c|}{$15-24$ (ref) } & \\
\hline $25-39$ & 0.465 & 0.190 & $1.592^{* *}$ & 0.650 & 0.298 & $1.916^{* *}$ \\
\hline $40-49$ & 1.113 & 0.263 & $3.043^{*}$ & 1.647 & 0.486 & $5.191^{\star}$ \\
\hline \multicolumn{7}{|c|}{ Level of Education } \\
\hline \multicolumn{7}{|c|}{ No Education (ref) } \\
\hline Primary & 0.214 & 0.296 & 1.239 & -0.615 & 0.504 & 0.541 \\
\hline Secondary & -0.241 & 0.343 & 0.786 & -0.716 & 0.330 & $0.489^{* *}$ \\
\hline Higher & -1.074 & 0.456 & $0.342^{* *}$ & -1.640 & 0.480 & $0.194^{*}$ \\
\hline \multicolumn{7}{|c|}{ Sex of Child } \\
\hline \multicolumn{7}{|c|}{ Male (ref) } \\
\hline Female & -0.333 & 0.156 & $0.717^{\star *}$ & -0.072 & 0.237 & 0.930 \\
\hline \multicolumn{7}{|c|}{ No. of under-five children in $H H$} \\
\hline \multicolumn{7}{|c|}{1 (one) (ref) } \\
\hline None & 4.426 & 0.184 & $83.67^{*}$ & 4.374 & 0.290 & $79.375^{*}$ \\
\hline $2-5$ & -0.767 & 0.363 & $0.464^{* *}$ & -0236 & 0.555 & 0.789 \\
\hline $6+$ & -16.246 & $22,720.880$ & 0.000 & -15.889 & 8139.982 & 0.000 \\
\hline \multicolumn{7}{|c|}{ Current use of Contraceptives } \\
\hline \multicolumn{7}{|c|}{ Using (ref) } \\
\hline Not Using & 0.689 & 0.169 & $1.992^{\star}$ & 1.445 & 0.287 & $4.241^{\star}$ \\
\hline \multicolumn{7}{|c|}{ Marital Status } \\
\hline \multicolumn{7}{|c|}{ Married (ref) } \\
\hline Not married & -0.447 & 0.275 & 0.639 & $\ldots \ldots$ & $\ldots \ldots$ & $\ldots \ldots$ \\
\hline Other $(\mathrm{D} / \mathrm{W} / \mathrm{S})$ & -0.541 & 0.222 & $0.582^{* *}$ & -0.181 & 0.530 & 0.835 \\
\hline
\end{tabular}

${ }^{*}$ Significance level $<0.01{ }^{*}$ Significance level $<0.05$. Source: Generated from 2014 Egypt and Kenya DHS datasets. 
There was a significant but negative relationship between mother's educational attainment and under-five mortality among women with higher education both in Kenya and in Egypt. Upon consideration of the effects of other independent variables, the study found that every increase in year of schooling, decreased the odds of mortality by 66 percent $(\mathrm{OR}=0.34)$ among women with higher education compared to those with no education in Kenya. In Egypt, the odds decreased by a multiplicative factor of $0.19(\mathrm{OR}=0.19)$ or 81 percent among women with higher education compared with those who had no education. Moreover, the study observed a negative but significant effect among women with secondary education where the odds of under-five mortality were 50 percent lower than among women without an education in Egypt.

Although sex of the child was significant, it was negatively associated with under-five deaths in Kenya. Having considered the effects of other independent variables, the probability of female children dying before their fifth birthday decreased by 28 percent compared to that of male children. In other words, male under-fives were at a higher risk of mortality in Kenya.

This study sought to determine the effect of number of under-five children in a household and childhood mortality. As shown in Table 3, a positive significant association between households with no under-five children and childhood mortality was observed in both countries. The odds of under-five deaths in households with no children of a similar age category were 84 times and 79 times higher in Kenya and Egypt respectively, relative to households with one under-five. In addition, the study observed a negative significant association between households with two to five under-fives and childhood mortality in Kenya, considering the effects of other independent variables. In this case, the odds of childhood death decreased by a multiplicative factor of 0.46 .

Use of contraceptives is a significant predictor of childhood survival. Considering the effects of other independent variables, non-use of contraception was positively and significantly associated with under-five mortality. The odds of under-five mortality doubled in Kenya and quadrupled in Egypt among non-users of contraception relative to current users.

Marital status was a significant predictor of under-five mortality in Kenya. There was a negative association between divorced, separated and widowed women and under-five mortality. After considering the effects of other independent variables, every year of widowhood, divorce or separation multiplied the odds of under-five mortality by 0.58 compared with the under-five mortality experiences of married women.

When all the study determinants were fitted on the regression model, region, place of residence and wealth index were insignificant predictors of childhood mortality in Kenya. Meanwhile, apart from region and place of residence, sex of child and marital status appeared to be insignificant predictors in Egypt as presented in Table 3. 


\section{Discussion}

Consistent with almost universal evidence in research, this study can confirm that mother's education is a significant predictor for reducing childhood mortality. This indicator is relevant for promotion of child rights, equitable child healthcare provision as well as child survival.

Research has provided overwhelming evidence globally that women's education plays a significant role in child health and survival [14] [19] [21] [23] [26]. A study involving countries in the East Mediterranean Region [18] noted that educated women were more likely to seek skilled antenatal and delivery care thus had better birth outcomes. In agreement, [24] in Bangladesh also explained that educated women would seek healthcare services and had better communication with healthcare workers compared to illiterate women. In other words, educated women would not entrust the health of their children to traditional medicines and beliefs. From Tanzania [6] wrapped up the evidence by stating that children born to women with secondary education had a 70 percent reduced risk of childhood deaths compared with those born to illiterate women. This evidence is consistent with the results of this study, where childhood mortality reduced by 66 percent and 81 percent among women with higher education in Kenya and Egypt, respectively compared to illiterate women.

Worldwide evidence consistently indicates that there is a close relationship between older mothers and the incidence of child mortality. This study found that women in their twilight reproductive ages $(40-49)$ were three and five times more likely to experience an under-five mortality than those below 25 years in Kenya and Egypt, respectively. This finding is consistent with results from similar studies in Egypt, Kenya, Ethiopia, Ghana and Saudi Arabia ([3] [15] [20] [25] [28]).

Use of contraceptives has a positive link to childhood survival. This is because contraception has been advocated as a life-saving strategy best suited for birth spacing and convenient for maternal and child health and survival. Contraception also helps women improve the household socio-economic wellbeing. This study found that women who were currently using contraception experienced lower childhood deaths in both countries. These results are consistent with a study in Bangladesh and another in Ghana [3] [24]. In Bangladesh, the study observed a 45 percent reduction in under-five mortality among children born to mothers who had ever used contraceptives compared with those who had never used.

This study observed an association between households with no under-five children and childhood mortality in both countries. In Kenya, the odds of under-five deaths in households with no children of a similar age category were 84 times higher than for households with one under-five while in Egypt, the odds were 79 times higher in the same category. However, the study also observed a negative significant association between households with two to five under-fives and childhood mortality where the likelihood of under-five deaths was lower 
compared with households with one under-five in Kenya. The latter result is inconsistent with that of Bangladesh which reported higher risks of under-five in households with two or more children under-five years compared to those with one under-five [24]. Overall, a 2017 study in Egypt [17] did not find any significant correlation between households with one or more under-fives and child mortality.

\section{Conclusion and Recommendation}

This study attempted to identify the most important determinants of under-five mortality in Egypt and Kenya by using descriptive analysis and multiple binary logistic regression models. Given its aim of identifying and comparing the key determinants of under-five mortality in the context of socio-demographic and behavioural characteristics of the mother as well as demographic characteristics of the new-born in Egypt and Kenya, the study depended on data from the Demographic and Health Surveys of 2014 in both countries. The study observed that over 60 percent of births were among women aged 25 - 39 in both countries. Moreover, women with higher education and those using contraception were less likely to experience under-five mortality.

The study concludes that women's education, contraceptive use and childbearing age are major indicators critical for equity, improvements in child survival, ending preventable child deaths and achieving the SDG target. The three indicators are interlinked: First, women who stay longer in school start childbearing later in life. Second, educated women are more likely to consider use of contraception to space and limit their births. Third, given the complications of old age childbearing, educated women are more likely to have their children before age 40 . While observing the recommended birth spacing intervals and considering their engagements in development and wealth creation, educated women are likely to have fewer children. This trend automatically lowers fertility and reduces a country's maternal and child healthcare burden. In turn, it accords an opportunity for a country to provide affordable and equitable quality healthcare services critical for child survival.

Considering the substantial evidence provided in this study on mother's education, age and contraceptive use in both countries (Egypt and Kenya), the following recommendations can be made: 1) both governments should prioritize and promote women's education in order to benefit from reduced under-five mortality. Educated women are more likely to improve household incomes and nutrition, reduce household poverty and ensure healthy children. 2) both governments should increase information and campaigns to encourage families, especially women to avoid births in later ages as too early or too late childbirths increase chances of maternal and child deaths due to increased chances of complications. 3) increased use of contraception is critical for improved child survival as well as prevent risky old age childbearing. Both governments should promote the use of contraceptives to space and limit births including reducing the 
unmet need for family planning. All these efforts have an overall net effect on reduced childhood mortality.

As earlier indicated, this study found incredibly significant association and very high odds between households with no under-five children and childhood mortality compared with households with one child in both countries. This study recommends further research in this area for better insight.

\section{Conflicts of Interest}

The authors declare no conflicts of interest.

\section{References}

[1] UN General Assembly (1989) Convention on the Rights of the Child. United Nations, Treaty Series, Vol. 1577, 3.

[2] World Health Organization (2018) World Health Statistics 2018: Monitoring Health for the SDGs, Sustainable Development Goals. Geneva.

[3] Kanmiki, E.W., Bawah, A.A., Agorinya, I., Achana, F.S., Awoonor-Williams, J.K., Oduro, A.R., Akazili, J., et al. (2014) Socio-Economic and Demographic Determinants of Under-Five Mortality in Rural Northern Ghana. BMC International Health and Human Rights, 14, 24. https://doi.org/10.1186/1472-698X-14-24

[4] Casterline, J.B., Cooksey, E.C. and Ismail, A.F. (1992) Infant and Child Mortality in Rural Egypt. Journal of Biosocial Science, 24, 245-260. https://doi.org/10.1017/S0021932000019763

[5] Ettarh, R. and Kimani, J. (2012) Determinants of Under-Five Mortality in Rural and Urban Kenya. https://doi.org/10.22605/RRH1812

[6] Nattey, C., Masanja, H. and Klipstein-Grobusch, K. (2013) Relationship between Household Socio-Economic Status and Under-Five Mortality in Rufiji DSS, Tanzania. Global Health Action, 6, 19278. https://doi.org/10.3402/gha.v6i0.19278

[7] UNICEF (2019) Child Survival and the SDGs.

[8] National Foreign Assessment Center (U.S.) and United States (1981) The World Factbook. Central Intelligence Agency, Washington DC.

https://doi.org/10.5812/ijp.10485

[9] Kenya National Bureau of Statistics (2019) The 2019 Kenya Population and Housing Census. Nairobi.

[10] PRB (2021) Population Reference Bureau Datasheet.

[11] Ministry of Health and Population [Egypt], El-Zanaty and Associates [Egypt], and ICF International (2015) Egypt Health Issues Survey 2015. Ministry of Health and Population and ICF International, Cairo, and Rockville.

[12] Kenya National Bureau of Statistics, Ministry of Health/Kenya, National AIDS Control Council/Kenya, Kenya Medical Research Institute, National Council for Population and Development/Kenya and ICF (2017) 2014 Kenya Demographic and Health Survey KDHS County-Level KDHS Data: Outputs from a DHS Workshop. Ministry of Health Kenya, Nairobi.

[13] United Nations Inter-Agency Group for Child Mortality Estimation (UN IGME) (2019) Levels \& Trends in Child Mortality: Report, Estimates Developed by the United Nations Inter-Agency Group for Child Mortality Estimation. United Nations Children's Fund, New York. 
[14] Lara, G.J. and Pullum, T.W. (2005) Infant Mortality in Egypt: Exploring the Role of Prenatal Care, and Implications for Public Policy. Population Association of America, Alexandria.

[15] Mansour, E., Eissa, A.N., Nofal, L.M., Kharboush, I. and Reda, A.A. (2005) Morbidity and Mortality of Low-Birth-Weight Infants in Egypt.

[16] Yasin, S. K. (2008) Socioeconomic and Bio-Demographic Determinants of Infant Mortality in Egypt. Doctoral Dissertation.

[17] Sultan, E.A., Shokair, N.F. and Teba, K.M. (2018) Prevalence, Determinants, and Health Service Utilization of "At Risk" Under-Five Children Attending a Family Health Center, Egypt 2017. Alexandria Journal of Pediatrics, 31, 34.

[18] Al-Shahethi, A.H., Bulgiba, A., Zaki, R.A., Al-Dubai, S.A.R., Al-Surimi, K.M. and Al-Serouri, A.A. (2018) Neonatal Mortality in the Eastern Mediterranean Region: Socio-Demographic, Economic and Perinatal Factors, 1990-2013. Iranian Journal of Pediatrics, 28, e10485.

[19] Yassin, K.M. (2000) Indices and Sociodemographic Determinants of Childhood Mortality in Rural Upper Egypt. Social Science \& Medicine, 51, 185-197. https://doi.org/10.1016/S0277-9536(99)00459-1

[20] Machio, P.M. (2018) Determinants of Neonatal and Under-Five Mortality in Kenya: Do Antenatal and Skilled Delivery Care Services Matter? Journal of African Development, 20, 59-67.

[21] Chepkwony, K.G. (2019) Factors Associated with Urban and Rural under Five Mortality Differentials in Kenya. Doctoral Dissertation, University of Nairobi, Nairobi.

[22] Ikamari, L.D. (2013) Regional Variation in Neonatal and Post-Neonatal Mortality in Kenya. African Population Studies, 27, 4-24. https://doi.org/10.11564/27-1-4

[23] Kirika, L. (2017) Determinants of Under-Five Mortalities among the Pastoralists in Kajiado, Kenya. European Journal of Research in Medical Sciences, 5, 13.

[24] Chowdhury, A.H. (2013) Determinants of Under-Five Mortality in Bangladesh. https://doi.org/10.4236/ojs.2013.33024

[25] Negera, A., Abelti, G., Bogale, T., Gebreselassie, T. and Pearson, R. (2013) An Analysis of the Trends, Differentials and Key Proximate Determinants of Infant and Under-Five Mortality in Ethiopia. ICF International, Calverton.

[26] Bado, A.R. and Susuman, A.S. (2016) Women's Education and Health Inequalities in Under-Five Mortality in Selected Sub-Saharan African Countries, 1990-2015. PLoS ONE, 11, e0159186. https://doi.org/10.1371/journal.pone.0159186

[27] Abate, M.G., Angaw, D.A. and Shaweno, T. (2020) Proximate Determinants of Infant Mortality in Ethiopia, 2016 Ethiopian Demographic and Health Surveys: Results from a Survival Analysis. Archives of Public Health, 78, Article No. 4. https://doi.org/10.1186/s13690-019-0387-4

[28] Al Mazrou, Y.Y., Khan, M.U. and Aziz, K.M.S. (1997) Determinants of Under-Five Mortality in Saudi Arabia. Saudi Medical Journal, 18, 31-36.

[29] Ali, M. (2020) Lecture Notes on Logistic Regression. Cairo Demographic Centre, Cairo.

[30] Hill, K. (2003) Frameworks for Studying the Determinants of Child Survival. Bulletin of the World Health Organization, 81, 138-139. 